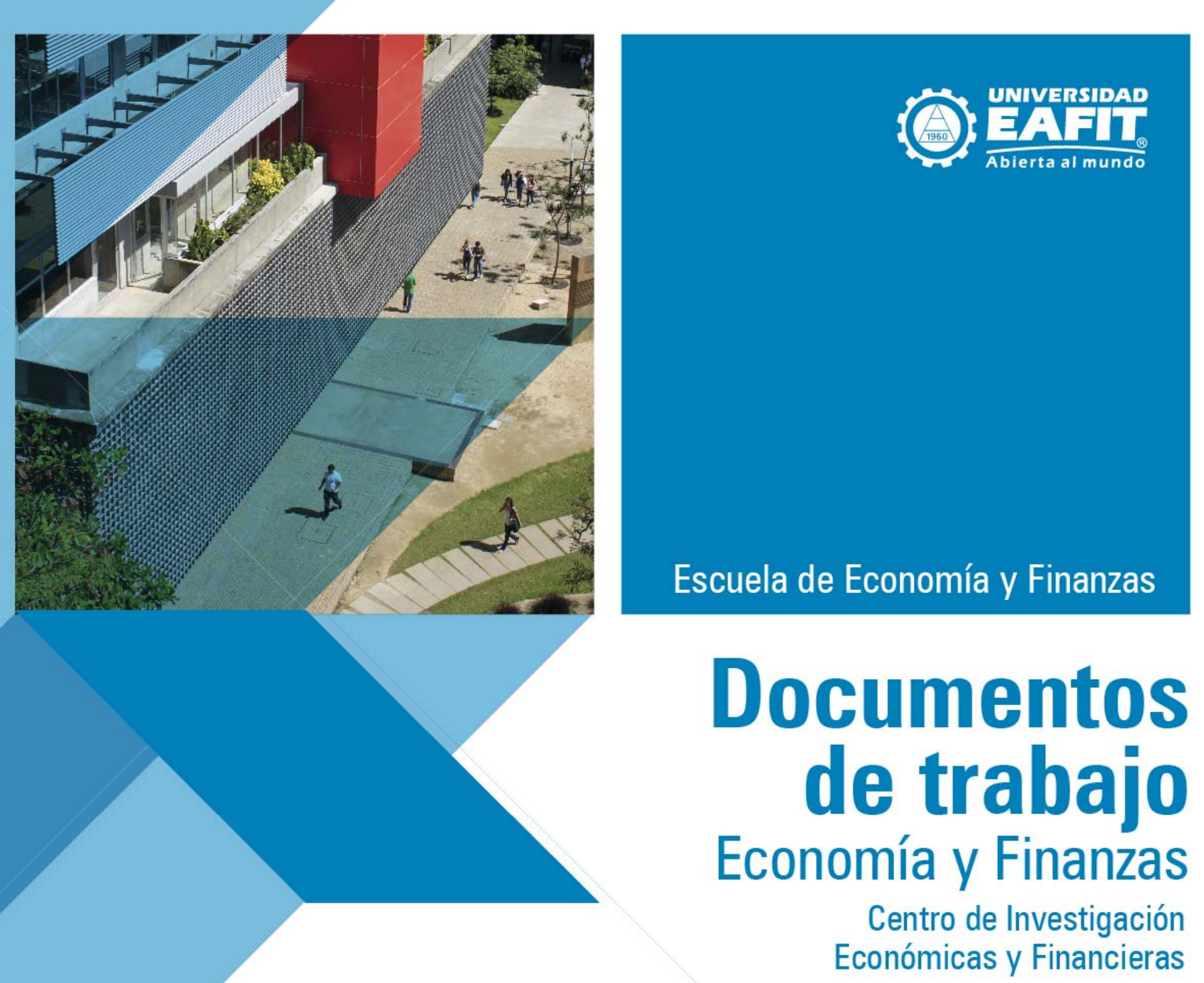

No. 12-33

Intellectual property rights, foreign direct 2012 investment and the shadow economy

Canavire, Gustavo; Saravia, Antonio; Rios-Avila, Fernando

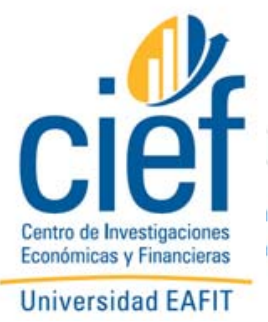




\title{
Intellectual property rights, foreign direct investment and the shadow economy
}

\author{
Antonio Saravia ${ }^{1, *}$ \\ Mercer University \\ Gustavo Canavire-Bacarreza \\ Universidad EAFIT \\ Fernando Rios-Avila \\ Levy Economics Institute of Bard College
}

\begin{abstract}
The relationship between intellectual property rights (IPR) protection and foreign direct investment (FDI) continues to pose a challenging puzzle. While several studies have found that these two variables are positively correlated, others have not been able to find conclusive results or have found that the relationship is actually negative. We contend that a partial explanation of these contradictory results resides on institutional differences among host countries. We find that increases in IPR protection encourage FDI in countries in which the shadow (informal) economy represents a relatively small percentage of the country's economy but it does not produce the same result in countries in which that percentage is relatively large. The size of the shadow economy is determined, in turn, by the quality of institutional variables such as the degree of bureaucracy, the level of corruption, and the extent of confiscatory taxation and political instability. We present empirical evidence supporting the results of our theoretical framework using threshold regression techniques on a sample of 94 countries and data for the 2000 - 2005 period.
\end{abstract}

Keywords: Intellectual Property Rights, Foreign Direct Investment, Shadow Economy, Informality JEL Classification: F230; O170; O340

\footnotetext{
${ }^{*}$ Corresponding author

Email addresses: saravia_av@mercer.edu (Antonio Saravia), gcanavir@eafit.edu.co (Gustavo Canavire-Bacarreza), friosavi@levy.org (Fernando Rios-Avila)
} 


\section{Introduction}

The relationship between intellectual property rights (IPR) protection and foreign direct investment (FDI) continues to pose a challenging puzzle. While several studies have found that there is a positive correlation between these two variables (e.g. Park and Ginarte (1997) and Branstetter and Saggi (2011)), others have not been able to find conclusive results (e.g. Braga and Fink (1999) and Javorcik (2004)) or have found that the relationship is actually negative (e.g. Glass and Saggi (2002), Rose-Ackerman and Tobin (2005) and Winchell (2007)).

The aforementioned results are not surprising when one considers that the relationship between IPR and FDI operates through multiple channels and is subject to regional and industry effects. Using data from transition economies, for example, Javorcik (2004) finds that weak IPR protection deters FDI in technology-intensive sectors but encourages FDI in distribution activities. Maskus (1998), in turn, finds that IPR protection encourages FDI when is accompanied by broader business-friendly policies which characterize developed countries but not their developing counterparts. Moreover, in a very influential article, Glass and Saggi (2002) argue that IPR protection may generate "resource wasting and imitation disincentive effects" that reduce both FDI inflows in developing countries and innovation in developed countries.

Conflicting arguments are also observed at the forefront of international trade negotiations. Developed countries and multilateral trade organizations continue to demand that developing countries adopt and enforce stricter IPR reforms. The latter typically negotiate for softer reforms and longer time horizons as they recognize that FDI depends on several other variables and the political economy of IPR reforms is complex and difficult to navigate.

Our aim in this paper is to contribute to this discussion from an institutional economics perspective. As in Glass and Saggi (2002), we argue that the effect of IPR protection on FDI is largely determined by the competition for domestic resources between multinational companies (MNCs) and illegal imitation activity. We depart from Glass and Saggi (2002), however, in that we propose that such competition is significantly determined by the size of the shadow (informal) economy where most illegal imitation activity takes place. ${ }^{1}$

Our argument is as follows. Carrying productive activities in the formal economy can be very costly when the institutional environment is inefficient (i.e. characterized by high levels of bureaucracy, corruption, confiscatory taxation, political instability, etc.). In this type of institutional environment firms and workers have incentives to replace their formal economic activities for informal economic activities including illegal imitation. As a result, the relative size of

\footnotetext{
${ }^{1}$ In the model proposed by Glass and Saggi (2002), the competition for resources between MNCs and illegal copiers is determined by technological restrictions. These authors argue that the production of imitation copies is subject to fixed input ratios. Therefore, as IPR protection increases, more resources (and not less) are devoted to imitation activity. Consequently, the availability of domestic resources for MNCs decreases and FDI is discouraged.
} 
the shadow economy tends to be relatively large. Olsen (2005), for example, report that illegal copies of pharmaceuticals, motion pictures, records, business and entertainment software in developing countries - where the shadow economy tends to be relatively large - represent $60 \%, 56 \%, 63 \%, 64 \%$, and $73 \%$ of the respective total number of copies sold in these countries. In this sense, the relative size of the shadow economy proxies the extent by which the quality of the institutional environment gives rise to informal/illegal imitation activity. Given that, as we mentioned above, illegal domestic imitation activity and MNCs compete for domestic resources, the size of the shadow economy inversely proxies the relative scarcity of resources available for MNCs in the formal economy. The latter significantly affects FDI. ${ }^{2}$

In this framework, IPR protection can be understood as an effort to reduce the size of the shadow economy where illegal imitation happens. IPR protection increases the cost of production for illegal copiers operating in the shadow economy and reduce their profit rates. Thus, in countries in which the shadow economy is relatively small (i.e. the institutional environment is relatively efficient) most illegal copiers would find optimal to abandon their informal imitation activities and return to the formal economy. As a result, the relative size of the shadow economy would decrease and the pool of resources available in the formal economy (e.g. the labor force) would increase. MNCs, therefore, would not only see their illegal competition reduced but also benefit from the increasing availability of resources available to them. FDI would then be strongly encouraged. The same is not necessarily true, however, in countries in which the shadow economy is relatively large (i.e. the institutional environment is relatively inefficient). In this case, excessive bureaucracy, corruption, confiscatory taxation and/or political instability impose a high barrier between the formal and shadow economies that illegal copiers may find difficult to overcome. While an increase in IPR protection reduces their profit rates, illegal copiers may continue to find optimal to remain operating in the shadow economy. As a result, both the reduction in illegal competition and the increase in the availability of resources for MNCs will tend to be smaller or null.

The empirical validation of this hypothesis will crucially depend on the definition of relatively small and relatively large shadow economies. Is there a cut-off point in the shadow economy distribution at which the relationship between IPR and FDI changes? A possible approach to this question consists on using the threshold regression methodology developed by Hansen $(1999,2000)$. This methodology allows for the identification of a threshold point in a variable's distribution at which the relationship between two other variables suffers a structural break. The obvious advantage of this methodology is that it lets the sample data determine the location of the cut-off point or threshold rather

\footnotetext{
${ }^{2}$ The correlation between the size of the shadow economy (Schneider et al. (2010)) and the Economic Freedom of the World Summary Index (Gwartney et al. (2007)) for the countries and years relevant for our study (2000-2005) is in the order of $-72 \%$.
} 
than requiring the researcher to impose it arbitrarily. ${ }^{3}$ We perform this analysis on a sample of 94 countries with data for the 2000 - 2005 period. In our baseline regression model, we find that a statistically significant threshold exists, indeed, at a value of $30.7 \%$ in the shadow economy size distribution (which ranges from $8.5 \%$ to $67.7 \%) .{ }^{4}$

Several studies have analyzed the effects of institutional variables on FDI. Wheeler and Mody (1992), Globerman and Shapiro (2002), Aizenman and Spiegel (2002) and Bénassy-Quéré et al. (2005) have studied the relationship of FDI with several indices of institutional quality including easiness to create a company, transparency, tax system, corruption, contract law, security of property rights, efficiency of justice and political risk. Some others have focused on specific determinants (e.g. Wei (1997) and Habib and Zurawicki (2002) have studied the effects of corruption) or specific regions (e.g. Kinoshita and Campos (2003) have studied the relationship between FDI and institutional variables in transition economies and Méon and Sekkat (2004) have done the same for MENA countries). As expected, most authors find that more efficient institutional environments tend to attract more FDI. We contribute to this literature by illustrating a particular channel through which the quality of the institutional environment affects FDI. We show that the institutional environment conditions the relationship between IPR protection and FDI by determining the relative size of the shadow economy where illegal copies are produced.

The next section presents a theoretical framework that illustrates the competition for resources between MNCs and illegal copiers. Section three presents the empirical strategy and results and section four concludes.

\section{Theoretical Framework}

Assume a market of a given product being served by two types of firms: MNCs and illegal copiers. ${ }^{5}$ MNCs establish themselves in the formal economy and produce original copies of the product. Illegal copiers establish themselves in the shadow economy and produce illegal imitations of the original copies produced by MNCs. Original copies and imitation copies are deemed qualityadjusted substitutes (if imitation copies are only half as good as original copies then two units of the former are equivalent to one unit of the latter).

We assume that MNCs are monopolistically competitive firms subject to a constant marginal cost $c(r)$, where $r$ represents the relative abundance of resources (e.g. labor) in the formal economy. An increase in $r$ shifts the marginal cost for MNCs downwards. As we will see below, $r$ increases when illegal copiers

\footnotetext{
${ }^{3}$ Falvey et al. (2006) use threshold regression analysis to study the effects of IPR protection on economic growth.

${ }^{4}$ As we explain below in more detail, these figures represent the size of the shadow economy as a percentage of GDP.

${ }^{5}$ This framework is based on the model of copyright protection developed by Landes and Posner (2003).
} 
abandon the shadow economy and switch to the formal economy as IPR protection increases.

We assume that illegal copiers operate in a perfectly competitive market subject to a constant marginal cost $m(z)$, where $z$ is an effective measure of IPR protection (i.e. it captures the degree of enforcement). An increase in $z$ shifts the marginal cost for illegal copiers upwards. Economic profits for illegal copier $j$ can be written as:

$$
\Pi_{j}=\left[p-m_{j}(z)\right] y_{j}-O(w)=0
$$

where $p$ is the price of a quality-adjusted imitation copy and $O(w)$ represents the opportunity cost faced by illegal copiers. This last variable is crucial for the model. The opportunity cost faced by illegal copiers is given by the utility or profits that illegal copiers could be earning in the formal economy. As argued in the previous section, $O(w)$ is a negative function of the size of the shadow economy (captured by $w$ ) or, which is the same, a positive function of the quality of the institutional environment.

It is then straightforward to illustrate the effects of an increase in IPR protection. Consider a developed country, $D$, characterized by a relatively small shadow economy (i.e. an efficient institutional environment), and a developing country, $U$, characterized by a relatively large shadow economy (i.e. an inefficient institutional environment). To simplify the analysis, assume that $w^{D}<w^{U} \Rightarrow O\left(w^{D}\right)>0$ and $O\left(w^{U}\right)<0$. Starting from long run equilibrium, introduce now a shock whereby both countries experience an increase in IPR protection ( $z$ goes up). As a result, accounting profits for illegal copiers in both countries, $\left[p-m_{j}(z)\right] y_{j}$, turn negative. Illegal copiers in both countries will then have incentives to quit their illegal imitation activities and move to the formal economy. Given, however, that $O\left(w^{D}\right)>0$ and $O\left(w^{U}\right)<0$, a larger number of illegal copiers will be expected to exit the shadow economy in country $D$ than in country $U$. Hence, the pool of resources in the formal economy will increase to a larger extent in country $D$ than in country $U$. This will lower the marginal cost faced by MNCs in country $D$ to a larger extent than in country $U$. In fact, if the institutional environment is highly deteriorated in country $U\left(O\left(w^{U}\right)\right.$ is large in absolute value), the effect on marginal cost for MNCs in country $U$ may be insignificant or null.

In summary, through less illegal competition and an increase in the resources available in the formal economy, an increase in IPR protection will increase profits for MNCs in country $D$ to a larger extent than in country $U$. Higher profits for MNCs, in turn, will encourage higher FDI. First, as existing MNCs turn more profitable, they will be more likely to increase their investments. Second, given that MNCs operate in monopolistic competition, an increase in profits starting from long run equilibrium implies that new MNCs will enter the market. ${ }^{6}$

\footnotetext{
${ }^{6}$ The derivation of profits for MNCs and the analysis of changes in those profits as IPR protection increases is presented in Appendix A.
} 


\section{Empirical Strategy}

The results of our theoretical framework suggest that IPR protection positively affects FDI in countries characterized by relatively small shadow economies to a larger extent than in countries characterized by relatively large shadow economies. In fact, in the latter case, the effect of IPR protection on FDI may be null.

In order to empirically investigate the aforementioned results we employ a specification that includes control variables standard in empirical FDI studies. Our sample includes an unbalanced panel of 94 countries and data for the years 2000 to 2005. As we explain below, the period of study is largely determined by the availability of data on IPR protection and the size of the shadow economy.

\subsection{Data}

\subsubsection{FDI}

To evaluate the robustness and the heterogeneity of the effect across sectors we employ two different definitions of FDI. Our baseline model uses FDI net inflows as share of GDP obtained from the World Development Indicators (WDI). Alternatively, we use U.S. outward FDI net inflows (share of host country's GDP) by industry (food, chemicals, metals, machinery, computers and services) obtained from the Bureau of Economic Analysis. These industries are selected to maximize data availability for the period of study.

\subsubsection{IPR Protection}

Our measure of IPR protection is the IPR Protection Index (IPR PI) obtained from the Economic Freedom of the World (EFW) 2007 Annual Report (Gwartney et al. (2007)). The IPR PI is measured on a 0 to 10 scale with 10 representing the strongest level of IPR protection. The IPR PI is available annually for the 2000 - 2005 period. Unfortunately, this index was discontinued with the release of the EFW 2008 Annual Report.

An alternative index of IPR protection commonly used is the Index of Patent Rights developed by Park and Ginarte (1997). Unfortunately, for the last decade, this index includes data only for the years 2000 and 2005. While this index includes data every five years from 1960 to 1995, such data does not coincide with our data on the informal economy and so we are unable to use this source.

\subsubsection{Shadow Economy}

Schneider et al. (2010) provides data on the size of the shadow economy as a percentage of GDP for 162 countries from 1999 to 2007. The characterization of the shadow economy used by Schneider et al. (2010) fits our institutional argument well. In fact, according to Schneider et al. (2010), some of the reasons for which a company would operate in the shadow economy include "avoiding having to meet certain legal labor market standards, such as minimum wages, maximum working hours, safety standards, etc.," and "avoiding complying with 
Table 1: Summary Statistics

\begin{tabular}{lccccc}
\hline & Mean & Std Dev & Min & Max & Corr to FDI \\
\hline FDI (\% GDP) & 3.757 & 4.709 & 0.024 & 41.941 & 1 \\
IPR PI & 5.205 & 2.159 & 0.9 & 9.6 & 0.170 \\
Shadow Economy & 30.604 & 13.909 & 8.5 & 67.7 & -0.097 \\
GDPpc & 8.618 & 1.537 & 5.341 & 11.285 & 0.161 \\
Population & 16.495 & 1.634 & 12.547 & 20.988 & -0.299 \\
Openness & 86.339 & 57.468 & 20.258 & 422.331 & 0.558 \\
GCF & 22.825 & 6.424 & 5.467 & 84.338 & 0.348 \\
Inflation & 5.342 & 6.948 & -5.355 & 54.915 & -0.148 \\
\hline
\end{tabular}

certain administrative procedures, such as completing statistical questionnaires or other administrative forms."

Consolidating our data on FDI, IPR protection and the shadow economy, our period of study is restricted to six years: 2000 to 2005 .

\subsubsection{Control Variables}

The control variables we use are standard in empirical FDI studies (see, for example, Bénassy-Quéré et al. (2005), Vijayakumar et al. (2010) and Blonigen and Piger (2011)).

We control for GDP per capita (GDPpc) (in logarithms and measured in constant 2005 dollars (source: WDI)), Population (in logarithms (source: The World Bank)), Openness (imports plus exports divided by GDP (source: The World Bank)), Gross Capital Formation (GCF) (share of GDP (source: WDI)), and Inflation (GDP deflator (source: WDI)).

Table 1 reports the summary statistics for the variables used in our analysis as well as their correlation with the dependent variable. Notice that the average level of FDI is approximately $3.8 \%$ with a minimum of $0.024 \%$ (Greece) and a maximum of $41.9 \%$ (Hong Kong). The average level of the IPR PI is 5.2 with a minimum of 0.9 (Haiti) and a maximum of 9.6 (Germany). As far as the shadow economy, the average level is approximately $31 \%$ with a minimum of $8.5 \%$ (Switzerland and the U.S.) and a maximum of $67.7 \%$ (Bolivia).

Notice as well that, for the entire sample, IPR PI is positively correlated with FDI while the size of the shadow economy is negatively correlated with the same variable. The control variables also present correlations with FDI that are consistent with the results of previous literature.

\subsection{Methodology}

As mentioned in the Introduction, we use the threshold regression methodology developed by Hansen $(1999,2000)$ to identify cut-off points or thresholds in the size of the shadow economy distribution at which the relationship between IPR PI and FDI suffers a structural break. 
This methodology uses a sample-splitting framework that allows endogenous identification and testing of changes in the slope when the threshold is not known a priori. The estimated threshold, provided it exists, is then interacted with the variable of interest and tested in a regression. Thus, our baseline threshold regression takes the following form:

$$
F D I_{i t}=\beta_{j} X_{j i t}+\alpha_{1} I P R_{i t} I\left(S h E_{i t} \leq \hat{\lambda}\right)+\alpha_{2} I P R_{i t} I\left(S h E_{i t}>\hat{\lambda}\right)+\mu_{i}+\nu_{t}+\epsilon_{i t}
$$

where $\mathrm{FDI}_{\mathrm{it}}$ is captured by FDI net inflows (\% GDP) in country $i$ and period $t$; $\mathrm{X}_{\mathrm{jit}}$ is a vector of control variables that include GDPpc, Population, Openness, GCF and Inflation; IPR it is IPR PI in country $i$ and period $t ; \mathrm{ShE}_{\mathrm{it}}$ is Schneider et al.'s (2010) measure of the size of the shadow economy in country $i$ and period $t ; \mu_{i}$ and $v_{t}$ are country and time specific fixed effects; and $\epsilon_{i t}$ is a well-behaved idiosyncratic error. Also, $\hat{\lambda}$ is the threshold/cut-off point in the ShE distribution.

The methodology divides the observations into two regimes depending on whether ShE is smaller or larger than $\hat{\lambda}$. Thus, the effect of IPR on FDI will be given by $\alpha_{1}$ for countries in the low shadow economy regime and by $\alpha_{2}$ for countries in the high shadow economy regime.

A grid search is used to determine the value of the threshold that minimizes the sum of squared errors of the model. More formally, we define the residual sum of squares of the model estimated for a threshold level as $S(\hat{\lambda})=u(\hat{\lambda})^{\prime} u(\hat{\lambda})$. Then the optimal threshold is given by $\hat{\lambda}=\arg \min S(\hat{\lambda})$. The grid search uses all the values within the 20th and 80th percentiles of the empirical distribution of the size of the shadow economy to guarantee a minimum number of observations in the sample falling above and below the threshold.

Having identified a potential threshold, it is important to determine whether the threshold effect is statistically significant. To this aim we test the hypothesis of no threshold effects, Ho: $\alpha_{1}=\alpha_{2}$. Given that the threshold value does not present a standard distribution, we follow Hansen (2000) and use a likelihood ratio statistic to test for the null hypothesis. The LR-statistic is defined as $L R_{0}=\left(S_{0}-S_{1}(\hat{\lambda})\right) / \sigma^{2}$ with $\sigma^{2}=S_{1}(\hat{\lambda}) / n(t-1)$. Where $S_{0}$ denotes the residual sum of squares for the model without a threshold and $\sigma^{2}$ is the estimated error variance in the presence of the threshold. The estimated value is compared to the critical values reported in Hansen (1999). The critical value is based on the asymptotic distribution of the LR-statistic which can be written as $\operatorname{Pr}(\zeta \leq x)=$ $(1-\exp (-x / 2))^{2}$. The inverse of this formula can be used to obtain the critical values based on $c(\alpha)=-2 \log (1-\lceil(1-\alpha))$.

\subsection{Results}

Table 2 presents the results of our baseline regression model using FDI net inflows (\% GDP) as the dependent variable. For an initial comparison, column 1 presents a parsimonious linear regression with no threshold effects. In this specification, IPR PI is positive and significantly correlated to FDI for the entire sample. As mentioned before, this result is consistent with several empirical studies performed in the past. Additionally, two control variables present 
a significant relationship with FDI: Population and GCF. In the latter case, the relationship is positive indicating that the internal formation of capital is complementary to FDI. This result has also been found in previous studies (see, for example, Krkoska (2001)). In the former case the relationship is negative indicating that countries with larger population levels attract less FDI. Given that our measure of FDI is the share of FDI on GDP, this results may be capturing the fact that countries with larger populations tend to present larger GDP levels. In fact, this last result disappears when we use U.S. outward FDI by industry as the dependent variable (see Table 3). Notice as well that the coefficient for the shadow economy, while negative, is not significantly correlated to FDI. Thus, in this specification, the size of the informal economy does not seem to have a direct effect on FDI.

Column 2 presents the results of the specification of interest as presented in equation (2). The application of the threshold methodology allows us to find a threshold value $(\hat{\lambda})$ at $30.7 \%$ in the shadow economy size distribution at which the relationship between IPR PI and FDI suffers a structural break. The threshold value found is significantly different from 0 at the 0.01 significance level. The threshold level splits the sample in two groups with almost the same number of countries in each. As an example, countries like the U.S., Germany, Australia and Norway fall below the threshold while countries such as Algeria, Bolivia, Egypt and Nigeria fall above it. ${ }^{7}$

Our results are consistent with the theoretical intuition developed above. We find that IPR PI is negative and not significantly correlated to FDI for countries with relatively large shadow economies. On the other hand, IPR PI is positive and significantly correlated to FDI for countries with relatively small shadow economies. In fact, in this last case, the coefficient estimate shows that the relationship between IPR PI and FDI is almost twice as large as the one found in column 1. Thus, for countries presenting relatively small shadow economies, a one point increase in IPR is associated with an increase of 0.64 percentage points in FDI. This effect is sizable as it represents a relative increase of $17 \%$ with respect to the average level of FDI of $3.76 \%$. The results in terms of the control variables and the size of the shadow economy are qualitatively similar to those found in column 1 . This suggests that, as predicted by the theoretical framework, the size of the shadow economy has an indirect effect on FDI though the determination of the relationship between IPR and FDI.

For an illustration of the results consider Figure 1 which plots the combinations of IPR PI and FDI for each country and period in the sample. Consistent with the results in column 1 of Table 2, and apart for a few outlying observations at the lower end of the IPR distribution, the figure suggests that IPR PI and FDI are, indeed, positively correlated. Perhaps the most striking aspect of

\footnotetext{
${ }^{7}$ The regression in column 2 does not control for fixed effects as a join test rejected the significance of those dummies indicating a "quiet" time span for the analysis.
} 
Table 2: Regression Results Dependent variable FDI (\% GDP)

\begin{tabular}{|c|c|c|}
\hline & (1) & $(2)$ \\
\hline IPR PI & $\begin{array}{c}0.3720^{* *} \\
(0.1752)\end{array}$ & \\
\hline $\operatorname{IPR}$ PI $(\operatorname{ShE}>=\hat{\lambda})$ & & $\begin{array}{l}-0.0239 \\
(0.2142)\end{array}$ \\
\hline $\operatorname{IPR} \mathrm{PI}(\mathrm{ShE}<\hat{\lambda})$ & & $\begin{array}{c}0.6428^{* *} \\
(0.2619)\end{array}$ \\
\hline Shadow Economy & $\begin{array}{l}-0.1604 \\
(0.3102)\end{array}$ & $\begin{array}{l}-0.3719 \\
(0.3096)\end{array}$ \\
\hline GDPpc & $\begin{array}{c}4.8020 \\
(3.5008)\end{array}$ & $\begin{array}{c}2.9853 \\
(3.0469)\end{array}$ \\
\hline Population & $\begin{array}{c}-14.0248^{*} \\
(7.3926)\end{array}$ & $\begin{array}{c}-13.8632^{*} \\
(7.0367)\end{array}$ \\
\hline Openness & $\begin{array}{c}0.0215 \\
(0.0218)\end{array}$ & $\begin{array}{c}0.0194 \\
(0.0217)\end{array}$ \\
\hline $\mathrm{GCF}$ & $\begin{array}{c}0.2687^{* * * *} \\
(0.0532)\end{array}$ & $\begin{array}{c}0.2766^{* * *} \\
(0.0512)\end{array}$ \\
\hline Inflation & $\begin{array}{c}0.0178 \\
(0.0158)\end{array}$ & $\begin{array}{c}0.0260 \\
(0.0177)\end{array}$ \\
\hline Constant & $\begin{array}{c}188.5982 \\
(127.9230)\end{array}$ & $\begin{array}{c}207.8339 \\
(126.0457)\end{array}$ \\
\hline $\begin{array}{l}\hat{\lambda} \\
\text { LR-statistic }\end{array}$ & & $\begin{array}{c}30.7 \% \\
149^{* * *}\end{array}$ \\
\hline Adjusted $\mathrm{R}^{2}$ & 0.137 & 0.159 \\
\hline Observations & 482 & 482 \\
\hline
\end{tabular}




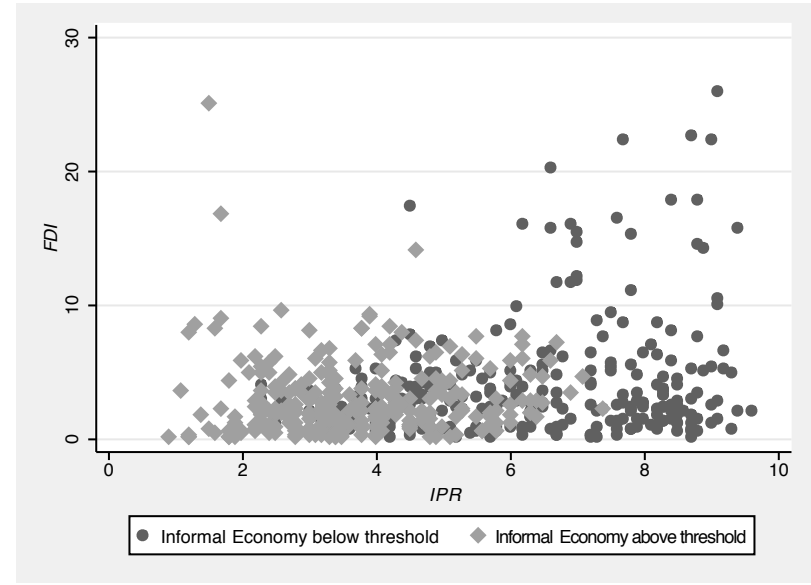

Figure 1: IPR PI vs. FDI

the graph, however, is its triangular property: FDI can take low and medium values at lower levels of IPR PI but it can take low, medium and high values at higher levels of IPR PI. In this sense, higher IPR PI levels command a higher likelihood of attracting higher FDI values but do not constitute a sufficient condition. This observation goes to the heart of our argument: the relationship between IPR protection and FDI depends on exogenous conditions. We claim that such exogenous conditions are partially given by the quality of the institutional environment.

To better visualize this idea, the sample is split by coloring with light gray the observations (countries/period) that present shadow economy sizes above the threshold of $30.7 \%$ and with dark grey the observations (countries/period) that fall below it. The relationship between IPR PI and FDI in the second group is more clearly positive than in the entire sample. It is, however, very difficult to identify any relationship between those two variables in the first group.

Table 3 presents the results when using U.S. outward FDI net inflows (share of host country's GDP) by industry as the dependent variable. The results are mixed but in most cases consistent with the theoretical intuition. We find thresholds levels ranging from $16 \%$ to $26.1 \%$ in the size of the shadow economy distribution. The regression using U.S. outward FDI in food, metals and services present results very similar to those in column 2 in Table 2 . That is, the coefficient of IPR PI is positive and significantly different from zero for countries presenting relatively small shadow economies but not for countries presenting relatively large shadow economies. In fact, for the case of services, the coefficient of IPR for countries presenting large shadow economies is not only negative but also significantly different from zero implying that increases in IPR PI are actually associated with lower levels of U.S. outward FDI. On the other hand, we do not find coefficients significantly different from zero above or below the 
Table 3: Regression Results - Dependent Variable: U.S. Outward FDI by Industry

\begin{tabular}{|c|c|c|c|c|c|c|}
\hline & $\begin{array}{c}(1) \\
\text { food }\end{array}$ & $\begin{array}{c}(2) \\
\text { chemicals }\end{array}$ & $\begin{array}{c}(3) \\
\text { metals }\end{array}$ & $\begin{array}{c}(4) \\
\text { machinery }\end{array}$ & $\begin{array}{c}(5) \\
\text { computers }\end{array}$ & $\begin{array}{c}(6) \\
\text { services }\end{array}$ \\
\hline IPR PI $(\mathrm{ShE}>=\hat{\lambda})$ & $\begin{array}{l}-0.009 \\
(0.009)\end{array}$ & $\begin{array}{c}-0.026 \\
(0.031)\end{array}$ & $\begin{array}{l}-0.000 \\
(0.003)\end{array}$ & $\begin{array}{c}0.000 \\
(0.005)\end{array}$ & $\begin{array}{c}-0.083 \\
(0.056)\end{array}$ & $\begin{array}{l}-0.024^{*} \\
(0.013)\end{array}$ \\
\hline $\operatorname{IPR} \mathrm{PI}(\mathrm{ShE}<\hat{\lambda})$ & $\begin{array}{c}0.024^{* *} \\
(0.010)\end{array}$ & $\begin{array}{l}-0.095 \\
(0.090)\end{array}$ & $\begin{array}{l}0.008^{*} \\
(0.004)\end{array}$ & $\begin{array}{c}0.018 \\
(0.011)\end{array}$ & $\begin{array}{c}0.076 \\
(0.101)\end{array}$ & $\begin{array}{l}0.030^{*} \\
(0.015)\end{array}$ \\
\hline Shadow Economy & $\begin{array}{c}0.016 \\
(0.016)\end{array}$ & $\begin{array}{c}0.032 \\
(0.037)\end{array}$ & $\begin{array}{l}-0.011 \\
(0.008)\end{array}$ & $\begin{array}{c}0.006 \\
(0.012)\end{array}$ & $\begin{array}{l}-0.248 \\
(0.172)\end{array}$ & $\begin{array}{c}0.018 \\
(0.026)\end{array}$ \\
\hline GDPpc & $\begin{array}{c}0.057 \\
(0.115)\end{array}$ & $\begin{array}{l}-0.119 \\
(0.860)\end{array}$ & $\begin{array}{l}-0.007 \\
(0.084)\end{array}$ & $\begin{array}{c}0.056 \\
(0.084)\end{array}$ & $\begin{array}{l}-2.715 \\
(1.825)\end{array}$ & $\begin{array}{l}0.530^{*} \\
(0.296)\end{array}$ \\
\hline Population & $\begin{array}{l}-0.076 \\
(0.503)\end{array}$ & $\begin{array}{c}2.038 \\
(1.220)\end{array}$ & $\begin{array}{l}-0.234 \\
(0.210)\end{array}$ & $\begin{array}{c}0.207 \\
(0.249)\end{array}$ & $\begin{array}{c}0.188 \\
(2.602)\end{array}$ & $\begin{array}{l}-0.024 \\
(0.723)\end{array}$ \\
\hline Openness & $\begin{array}{l}-0.001 \\
(0.000)\end{array}$ & $\begin{array}{c}0.003 \\
(0.003)\end{array}$ & $\begin{array}{c}-0.001^{* *} \\
(0.000)\end{array}$ & $\begin{array}{c}0.000 \\
(0.001)\end{array}$ & $\begin{array}{l}-0.021 \\
(0.014)\end{array}$ & $\begin{array}{c}0.002 \\
(0.001)\end{array}$ \\
\hline GCF & $\begin{array}{l}-0.000 \\
(0.002)\end{array}$ & $\begin{array}{c}-0.024^{*} \\
(0.012)\end{array}$ & $\begin{array}{c}0.002 \\
(0.003)\end{array}$ & $\begin{array}{l}-0.002 \\
(0.004)\end{array}$ & $\begin{array}{l}0.068^{*} \\
(0.039)\end{array}$ & $\begin{array}{c}-0.018^{* *} \\
(0.008)\end{array}$ \\
\hline Inflation & $\begin{array}{l}-0.001 \\
(0.001)\end{array}$ & $\begin{array}{l}-0.003 \\
(0.002)\end{array}$ & $\begin{array}{c}0.000 \\
(0.000)\end{array}$ & $\begin{array}{l}-0.001 \\
(0.001)\end{array}$ & $\begin{array}{c}0.015 \\
(0.012)\end{array}$ & $\begin{array}{l}-0.002 \\
(0.001)\end{array}$ \\
\hline Constant & $\begin{array}{c}0.419 \\
(8.115)\end{array}$ & $\begin{array}{c}-33.509^{*} \\
(17.674)\end{array}$ & $\begin{array}{c}4.407 \\
(3.794)\end{array}$ & $\begin{array}{l}-4.116 \\
(4.541)\end{array}$ & $\begin{array}{c}29.417 \\
(48.880)\end{array}$ & $\begin{array}{c}-4.665 \\
(12.197)\end{array}$ \\
\hline$\hat{\lambda}$ & 26.1 & 16 & 25.79 & 18.6 & 16.6 & 26.1 \\
\hline LR-statistic & $11.543^{* * *}$ & $22.093^{* * *}$ & 2.602 & $30.613^{* * *}$ & $9.470^{* *}$ & $15.174^{* * *}$ \\
\hline Adjusted $\mathrm{R}^{2}$ & 0.041 & 0.124 & 0.074 & 0.138 & 0.248 & 0.210 \\
\hline Observations & 237 & 248 & 214 & 241 & 235 & 257 \\
\hline
\end{tabular}

threshold for chemicals, machinery and computers.

Further robustness tests to our baseline specification are performed in Table B1 in Appendix B. The results are robust and stable to the inclusion of a year lag for GDPpc, Inflation and Population. We perform this test as it could be argued that there are potential endogenous effects of these variables with FDI. Finally, we also test the presence of a threshold using the percentage change in FDI as the dependent variable instead of its level. In all cases, the results are qualitatively similar to those in column 2 of Table 2 . 


\section{Conclusion}

The relationship between IPR protection and FDI continues to pose a challenging puzzle at both the academic and public policy forefronts. We contribute to this discussion from an institutional economics perspective.

Our argument is as follows. Carrying productive activities in the formal economy can be very costly when the institutional environment is inefficient (i.e. characterized by high levels of bureaucracy, corruption, confiscatory taxation, political instability, etc.). In this type of institutional environments firms and workers have incentives to replace their formal economic activities for informal economic activities including illegal imitation. As a result, the relative size of the shadow economy tends to be relatively large. Given that illegal domestic imitation activity and MNCs compete for local resources, the size of the shadow economy inversely proxies the relative scarcity of resources available for MNCs in the formal economy. The latter significantly affects FDI.

In this framework, IPR protection can be understood as an effort to reduce the size of the shadow economy where illegal imitation happens. IPR protection increases the cost of production for illegal copiers operating in the shadow economy and reduce their profit rates. Thus, in countries in which the shadow economy is relatively small (i.e. the institutional environment is relatively efficient) most illegal copiers would find optimal to abandon their informal imitation activities and return to the formal economy. As a result, the relative size of the shadow economy would decrease and the pool of resources available in the formal economy (e.g. the labor force) would increase. MNCs, therefore, would not only see their illegal competition reduced but also benefit from the increasing availability of resources. FDI would be strongly encouraged. The same is not necessarily true, however, in countries in which the shadow economy is relatively large (i.e. the institutional environment is relatively inefficient). In this case, excessive bureaucracy, corruption, confiscatory taxation and/or political instability impose a high barrier between the formal and shadow economies that illegal copiers may find difficult to overcome. While an increase in IPR protection reduces their profit rates, illegal copiers may continue to find optimal to remain operating in the shadow economy. As a result, both the reduction in illegal competition and the increase in the availability of resources for MNCs will tend to be smaller or null.

Using threshold regression analysis, we find a significant threshold or cutoff point at a level of $30.7 \%$ in the shadow economy size distribution at which the relationship between IPR protection and FDI suffers a structural break. Consistent with the theoretical intuition, the results show that IPR protection is negative and not significantly correlated to FDI (as a percentage of GDP) for countries with relatively large shadow economies. On the other hand, IPR protection is positive and significantly correlated to FDI for countries with relatively small shadow economies. In fact, in this last case, the coefficient estimate shows that the relationship between IPR protection and FDI is almost twice as large as the one found in a simple linear regression with no threshold effects. For our sample and period of study, in countries presenting relatively small shadow 
economies, a one point increase in IPR protection is associated with an increase of 0.64 percentage points in FDI. This effect is sizable as it represents a relative increase of $17 \%$ with respect to the average level of FDI of $3.76 \%$.

We further explore the relationship between IPR protection and FDI by using U.S. outward FDI by industries. The results are mixed but in most cases consistent with the theoretical intuition. In all cases, we find thresholds levels significantly different from zero ranging from $16 \%$ to $26.1 \%$ in the shadow economy size distribution. The regression using U.S. outward FDI in food, metals and services present results very similar to those found in our baseline regression. That is, the coefficient of IPR is positive and significantly different from zero for countries presenting relatively small shadow economies but not for countries presenting relatively large shadow economies. In fact, for the case of services, the coefficient of IPR for countries presenting large shadow economies is not only negative but also significantly different from zero implying that increases in IPR protection are actually associated with lower levels of U.S. outward FDI. On the other hand, we do not find coefficients significantly different from zero above or below the threshold for chemicals, machinery and computers.

The results are robust and stable to the inclusion of a year lag for GDPpc, Inflation and Population as well as the use of percentage changes in FDI as the dependent variable.

\section{References}

Aizenman, J. and Spiegel, M. M. (2002), Institutional efficiency, monitoring costs and the investment share of FDI, Working paper, National Bureau of Economic Research. No. 9324.

Bénassy-Quéré, A., Coupet, M. and Mayer, T. (2005), Institutional Determinants of FDI, Working paper, CEPII. (5).

Blonigen, B. and Piger, J. (2011), Determinants of foreign direct investment, Working paper, Cambridge, Mass.: National Bureau of Economic Research. No. 16704.

Braga, C. P. and Fink, C. (1999), 'How stronger protection of intellectual property rights affects international trade flows', World Bank Policy Research Working Paper (2051).

Branstetter, L. and Saggi, K. (2011), 'Intellectual property rights, foreign direct investment and industrial development*', The Economic Journal 121(555), 1161-1191.

Falvey, R., Foster, N. and Greenaway, D. (2006), 'Intellectual property rights and economic growth', Review of Development Economics 10(4), 700-719.

Glass, J. and Saggi, K. (2002), 'Intellectual property rights and foreign direct investment', Journal of International Economics 56(2), 387-410. 
Globerman, S. and Shapiro, D. (2002), National political infrastructure and foreign direct investment, Ottawa: Industry Canada.

Gwartney, J., Lawson, R., with Hall, J., Sobel, R. and Leeson, P. (2007), Economic Freedom of the World: 2007 Annual Report, Vancouver, BC: The Fraser Institute. Data retrieved from www.freetheworld.com.

Habib, M. and Zurawicki, L. (2002), 'Corruption and foreign direct investment', Journal of international business studies pp. 291-307.

Hansen, B. E. (1999), 'Threshold effects in non-dynamic panels: Estimation, testing, and inference', Journal of econometrics 93(2), 345-368.

Hansen, B. E. (2000), 'Sample splitting and threshold estimation', Econometrica pp. 575-603.

Javorcik, B. S. (2004), 'Does Foreign Direct Investment Increase the Productivity of Domestic Firms? In Search of Spillovers Through Backward Linkages', American Economic Review 94(3), 605-627.

Kinoshita, Y. and Campos, N. F. (2003), 'Why does FDI go where it goes? New evidence from the transition economies'.

Krkoska, L. (2001), Foreign Direct Investment Financing of Capital Formation in Central and Eastern Europe, Working paper, EBRD. No. 67.

Landes, W. and Posner, R. (2003), The economic structure of intellectual property law, Cambridge, Mass.: Harvard University Press.

Maskus, K. E. (1998), 'Role of intellectual property rights in encouraging foreign direct investment and technology transfer', Duke Journal of Comparative 83 International Law 9(1), 109-162.

Méon, P. G. and Sekkat, K. (2004), 'Does the quality of institutions limit the MENA's integration in the world economy?', The World Economy 27(9), 1475-1498.

Olsen, K. (2005), Counterfeiting and piracy: Measurement issues, in 'WIPO/OECD Expert Meeting on Measurement and Statistical Issues', Geneva.

Park, W. G. and Ginarte, J. C. (1997), 'Intellectual property rights and economic growth', Contemporary Economic Policy 15(3), 51-61.

Rose-Ackerman, S. and Tobin, J. (2005), 'Foreign direct investment and the business environment in developing countries: The impact of bilateral investment treaties', Yale Law \& Economics Research Paper (293).

Schneider, F., Buehn, A. and Montenegro, C. E. (2010), 'New Estimates for the Shadow Economies all over the World', International Economic Journal 24(4), 443-461. 
The World Bank Data Catalogue (n.d.).

URL: http://data.worldbank.org

Vijayakumar, N., Perumal, S. and Rao, K. C. (2010), 'Determinants of FDI in BRICS Countries: A panel analysis', International Journal of Business Science and Applied Management 5(3), 1-13.

Wei, S. J. (1997), Why is corruption so much more taxing than tax?: Arbitrariness kills, Working paper, Cambridge, MA: National Bureau of Economic Research. No. 6255.

Wheeler, D. and Mody, A. (1992), 'International investment location decisions: The case of US firms', Journal of international economics 33(1), 57-76.

Winchell, J. (2007), Determinants of foreign direct investment in developing countries: Bilateral investment treaties and intellectual property rights, in 'annual meeting of the International Studies Association 48th Annual Convention'. 


\section{Appendix A: Profits for MNCs}

Profits for a representative $\mathrm{MNC}, i$, are given by:

$$
\Pi_{i}=\left[p-c_{i}(z)\right][q(p)-y(p, z)]
$$

where $p$ is the price of a copy (original or quality-adjusted imitation), $y$ the aggregate supply of illegal imitation copies, and $q(p)$ the total market demand for copies. ${ }^{8}$

The price level that maximizes these profits solves:

$$
[q(p)-y(p, z)]+\left[p-c_{i}(z)\right]\left(\frac{d q}{d p}-\frac{d y}{d p}\right)=0
$$

which can be re-written as:

$$
p\left[1-\frac{G}{\left|\epsilon^{d}\right|+\epsilon^{s}(1-G)}\right]=c(z)
$$

where $G$ is the fraction of original copies out of total copies produced, $\epsilon^{d}=$ $q_{p}(p / q)$ is the price elasticity of demand, and $\epsilon^{s}=y_{p}(p / y)$ is the price elasticity of total supply by illegal copiers. ${ }^{9}$

The change in $\Pi_{i}$ as IPR protection increases is:

$$
\frac{d \Pi_{i}}{d z}=\left[\frac{d p}{d z}-\frac{d c}{d z}\right][q(p)-y(p, z)]+[p-c(z)]\left[\frac{d q}{d p} \frac{d p}{d z}-\left(\frac{d y}{d p} \frac{d p}{d z}+\frac{d y}{d z}\right)\right]
$$

Assuming the first-order profit maximizing condition:

$$
\frac{d \Pi_{i}}{d z}=-[p-c(z)] \frac{d y}{d z}-\frac{d c}{d z}[q(p)-y(p, z)]>0
$$

Thus, the size of $d \Pi_{i} / d z$ is determined by the absolute values of $d y / d z$ and $d c / d z$. In countries with relatively small shadow economies, these two expressions are bigger than in countries with relatively large shadow economies.

\footnotetext{
${ }^{8}$ Obviously, $d y / d p>0, d y / d z<0$, and $|d y / d z|^{s s}>|d y / d z|^{l s}$, where $s s$ stands for small shadow economy and $l s$ for large shadow economy.

${ }^{9}$ The second-order condition is $\partial^{2} \Pi / \partial p^{2}=2\left(q_{p}-y_{p}\right)+(p-c(z))\left(q_{p} p-y_{p} p\right)$, which is assumed to be less than zero.
} 


\section{Appendix B: Robustness Tests}

Table B1: Regression Results Alternative Specifications

\begin{tabular}{|c|c|c|c|c|}
\hline & $\begin{array}{c}(1) \\
\text { FDI }(\% \mathrm{GDP})\end{array}$ & $\begin{array}{c}(2) \\
\text { FDI }(\% \mathrm{GDP})\end{array}$ & $\begin{array}{c}(3) \\
\text { FDI }(\% \mathrm{GDP})\end{array}$ & $\begin{array}{c}(4) \\
\% \text { Diff FDI }\end{array}$ \\
\hline $\operatorname{IPR}(\mathrm{ShE}>=\hat{\lambda})$ & $\begin{array}{c}-0.0089 \\
(0.2093)\end{array}$ & $\begin{array}{c}0.0177 \\
(0.2082)\end{array}$ & $\begin{array}{c}0.1750 \\
(0.2325)\end{array}$ & $\begin{array}{c}0.0491 \\
(0.0619)\end{array}$ \\
\hline $\operatorname{IPR}(\operatorname{ShE}<\hat{\lambda})$ & $\begin{array}{c}0.6630^{* *} \\
(0.2527)\end{array}$ & $\begin{array}{c}0.6916^{* * *} \\
(0.2511)\end{array}$ & $\begin{array}{c}0.7772^{* * *} \\
(0.2591)\end{array}$ & $\begin{array}{c}0.1457^{* *} \\
(0.0611)\end{array}$ \\
\hline Shadow Economy & $\begin{array}{c}-0.6024^{* *} \\
(0.3026)\end{array}$ & $\begin{array}{c}-0.6464^{* *} \\
(0.3082)\end{array}$ & $\begin{array}{l}-0.6456^{*} \\
(0.3579)\end{array}$ & $\begin{array}{l}-0.1039 \\
(0.0838)\end{array}$ \\
\hline GDPpc & & & & $\begin{array}{c}0.1521 \\
(0.7507)\end{array}$ \\
\hline Population & $\begin{array}{c}-16.7017^{* *} \\
(6.7946)\end{array}$ & & & $\begin{array}{l}-1.5563 \\
(1.4922)\end{array}$ \\
\hline Openness & $\begin{array}{c}0.0266 \\
(0.0217)\end{array}$ & $\begin{array}{c}0.0270 \\
(0.0218)\end{array}$ & $\begin{array}{c}0.0371 \\
(0.0279)\end{array}$ & $\begin{array}{c}0.0072^{* *} \\
(0.0033)\end{array}$ \\
\hline $\mathrm{GCF}$ & $\begin{array}{c}0.2680^{* * * *} \\
(0.0518)\end{array}$ & $\begin{array}{c}0.2637^{* * * *} \\
(0.0521)\end{array}$ & & $\begin{array}{c}0.0194^{* *} \\
(0.0096)\end{array}$ \\
\hline Inflation & $\begin{array}{c}0.0303 \\
(0.0188)\end{array}$ & $\begin{array}{l}0.0327^{*} \\
(0.0186)\end{array}$ & $\begin{array}{c}0.0263 \\
(0.0192)\end{array}$ & $\begin{array}{c}0.0068 \\
(0.0054)\end{array}$ \\
\hline Lag GDPpc & $\begin{array}{c}0.2328 \\
(2.9166)\end{array}$ & $\begin{array}{c}0.0339 \\
(2.9251)\end{array}$ & $\begin{array}{c}1.4844 \\
(2.6132)\end{array}$ & \\
\hline Lag Population & & $\begin{array}{c}-19.5168^{* * *} \\
(6.8937)\end{array}$ & $\begin{array}{c}-24.8837^{* * *} \\
(8.3443)\end{array}$ & \\
\hline Lag GCF & & & $\begin{array}{l}-0.0048 \\
(0.0684)\end{array}$ & \\
\hline Constant & $\begin{array}{c}285.1628^{* *} \\
(120.0978)\end{array}$ & $\begin{array}{c}334.3871^{* * *} \\
(124.0927)\end{array}$ & $\begin{array}{c}415.1369^{* * *} \\
(146.9159)\end{array}$ & $\begin{array}{c}26.0732 \\
(26.4472)\end{array}$ \\
\hline$\hat{\lambda}$ & 30.7 & 30.7 & 30.7 & 27.6 \\
\hline LR-statistic & $13.619^{* * *}$ & $13.783^{* * *}$ & $10.249^{* *}$ & $8.295^{* *}$ \\
\hline Adjusted $\mathrm{R}^{2}$ & 0.162 & 0.167 & 0.099 & 0.032 \\
\hline Observations & 471 & 471 & 470 & 468 \\
\hline
\end{tabular}

Standard errors in parenthesis

Statistical significance: ${ }^{*} p<0.1,{ }^{* *} p<0.05,{ }^{* * *} p<0.01$

All regressions include country fixed effects 